\title{
Michael Boudreau, Peter G. Toner, and Tony Tremblay, eds. Exploring the Dimensions of Self-Sufficiency for New Brunswick (Fredericton: New Brunswick Atlantic Studies Research and Development Centre, 2009)
}

It is provocative when a piece of academic work can be organized in a manner to provide an objective, in-depth perspective into the public policy decision making process. Exploring the Dimensions of Self-Sufficiency for New Brunswick sets out to accomplish this by bringing together a compilation of multi-disciplinary academic essays that explore the New Brunswick government's new policy framework, Our Action Plan To Be Self-Sufficient in New Brunswick (2007). Examining the nature of self-sufficiency and its impact on the province and its people, these essays provide historical and contemporary insights into New Brunswick's economic, social and political setting. The commonality that resonates throughout this volume is that the province possesses a complexity and uniqueness which plays an important role in the province's self-sufficiency. In the opinion of the authors, these qualities are not given enough consideration in the new Action Plan.

The book is organized along the four main transformations outlined in New Brunswick's Action Plan: transformation of the economy; the workforce; relationships and the government. The first section "Critiquing our Economy," critically examines the Action Plan's proposal to "secure the base upon which our economy is built and branch out into new fields." (Action Plan, 14) The essays clearly demonstrate that the well established industries, such as forestry, and those that promise a future, need careful historical and contemporary analysis before providing policy support. For example, Mark J. McLaughlin and Bill Parenteau examine the issue of the province's pulp and paper industry by charting its evolution throughout the twentieth century. They focus on the period from 1960 to present during which time expansion within the industry depended heavily on provincial subsidies. The authors argue the government support for a strong manufacturing pulp and paper industry has strained the relationships with wood producers and rural communities, and they question the capacity of the industry to contribute to the self-sufficiency of the province. Looking at a newer industry, Joan McFarland examines the call centre industry in New Brunswick. She argues the industry is "vulnerable" and offers "unstable jobs," because it has already reached its peak for employment and is now in a steady decline as companies relocate due to market shifts.

The second section of the volume "Scrutinizing our Workforce," responds to the Action Plan's proposal to make "transformative changes in our [New Brunswickers'] workplaces, our post-secondary institutions, our schools and our communities." (Action Plan, 22) The essays in this section unveil the complexity of New Brunswick's formal and informal economy, and the changes that have shaped working life within the province. Bonnie Huskins and Michael 
Boudreau argue that the balance between the support mechanisms of the welfare state and the informal economic practices of family and community that evolved during the Post World War II period has already created a sustainable environment for working-class families. Surveying the difficult issue of outmigration, Greg Marquis examines past attempts by the provincial government to stabilize the province's population. He challenges the perceived conception of the current population "crisis" by arguing that the crisis is a social construct of both the state and industries in an attempt to attract a cheap and exploitable workforce to the province. The authors in this section generally agree that the workforce in New Brunswick is unique, shaped by culture, region and specific historical events that has formed a model of self-sufficiency on its own.

The authors in the third section "Reconceptualising Relationships," challenge the notion of self-sufficiency by calling for a close examination of New Brunswick's communities and cultural identity. Erin Hancock provides an analysis of how community-owned and operated co-operative enterprises play an important role in many areas by providing local employment and service delivery. Greg Leblanc argues the current economic, as well as environmental, social and cultural plans for the development of New Brunswick must grow beyond mere self-sufficiency to become truly sustainable. Weighing in on the question of the province's cultural identity, Thomas Hodd highlights that the province's plan for self-sufficiency lacks any in-depth notion of how to promote New Brunswick's cultural infrastructure. This section's examination of intra-provincial relationships among communities, the people's cultural and creative identities and the looming question of how to bridge self-sufficiency to sustainable development references the province's unique properties when critiquing the government's new policy framework.

Finally, the fourth section of this compilation "Deconstructing Government," has an interesting variety of essays that critique the Action Plan's aim to restructure government for "strong policy development, principled decision-making and the timely delivery of quality public services." (Action Plan, 29) Exploring the question of quality public services, Jane Jenkins provides a historical view of New Brunswick's cutting edge public health system in the early twentieth century, and how it came to an end with the advent of federally controlled public health that marked the end of the province's autonomy.

New Brunswick's aim to achieve self-sufficiency is not a new government policy. In the post World War II era the federal and provincial governments assumed responsibility to counteract regional underdevelopment in the provinces. New Brunswick has witnessed a long history of postwar provincial development policies that go hand in hand with the birth and expansion of federal agencies, policies, and programs designed to develop the Maritimes, including equalization payments. As the Action Plan states, "self-sufficiency" will be achieved when the province is no longer reliant on federal transfers and no 
longer christened a "have not" province. The New Brunswick government agrees that one of the most important components of self-sufficiency is the province's relationship and position within the federal nation-state.

This book provides some thoughtful and important insights into New Brunswick's new policy direction to achieve self-sufficiency. Two areas that were not discussed were New Brunswick's past provincial policies that were designed to stimulate growth, and an analysis of the impact of federal policies and institutions on the province (there is a well developed body of literature in this area). Including an analysis of why provincial development policy failed in the past and an examination of the province's underdevelopment in relation to its position within the federation, would have made his volume stronger. While this is an area that could have been explored further, this work is an excellent and thorough compilation that will be widely appreciated among the academic community and will hopefully find its way to provincial policy analysts and decision makers.

Adrian Egbers Dalhousie University

\section{Max Foran, Ed. Icon, Brand, Myth: The Calgary Stampede (Edmonton: AU Press, 2008).}

The Calgary Stampede is one of western Canada's most popular cultural festivals, and a book like Icon, Brand, Myth: The Calgary Stampede has been much anticipated. Icon, Brand, Myth is a compilation of essays that explore the cultural significance of one of the longest-running western entertainments in North America from its founding as an agricultural exhibition in the 1880s until the present. While the literature on American rodeos and frontier day festivals is relatively rich, a consideration of Canada's grand celebration of western culture has been neglected. Recently, the Calgary Stampede has received more academic attention and, as divulged in the introduction, this book is the product of a course on the Calgary Exhibition and Stampede formerly offered by University of Calgary's Faculty of Communication and Culture. Each of the books' contributors were either lecturers or "the subject of reference" in Stampede courses offered from 2004-2006 (ix).

The collection opens with an overview of Stampede history and Max Foran, the book's editor, provides the historical context for its origin and evolution. As one might expect, chapters include topics such as the establishment of the agricultural exhibition, the rodeo, cowboys, and the famous chuckwagon race. The book, however, moves beyond what might be considered traditional Stampede fare and other chapters explore the midway, parading culture, Calgary's public monuments, the Stampede's relationship with the city, the Stampede's role 